\title{
Optimization of Co-Gasification Process in an Entrained-Flow Gasifier Using the Taguchi Method*
}

\author{
Chih-Jung CHEN** and Chen-I HUNG** \\ **Department of Mechanical Engineering, National Cheng Kung University, Tainan 701, Taiwan, ROC \\ No.1, Ta-Hsueh Road, Tainan 701, Taiwan. \\ E-mail: cihung@mail.ncku.edu.tw
}

\begin{abstract}
Gasification has played an important role in the development of clean coal technology. To seek appropriate operations for synthesis gas (syngas) formation, the present study developed an optimization analysis procedure of the gasification process in an entrained-flow gasifier through the application of the Taguchi method in conjunction with a simulation method. The effects of the wall temperature, $\mathrm{O} / \mathrm{F}$ ratio, feed type and pressure on the performance of cold gas efficiency (CGE) were investigated. An orthogonal array was used to arrange the CFD experimental plan for the above factors. Analysis of the signal-to-noise ratio ( $\mathrm{S} / \mathrm{N}$ ratio) was used to evaluate the calculation results. Results suggest that the optimum conditions are a wall temperature of $1500 \mathrm{~K}$, an $\mathrm{O} / \mathrm{F}$ ratio of 0.6 , coal feed type and a gasifier pressure of $3 \mathrm{MPa}$. The influence strength order of each control condition is feed type $>\mathrm{O} / \mathrm{F}$ ratio $>$ wall temperature $>$ pressure. The value of the $\mathrm{S} / \mathrm{N}$ ratio for the optimum case is 13.40 , which is the highest value compared to other cases. Findings show that the Taguchi method is able to investigate the gasification process well and can therefore be applied in future studies conducted in various fields.
\end{abstract}

Key words: Co-Gasification, Entrained-Flow Gasifier, Taguchi Method, Coal Gas Efficiency, Numerical Simulation, Clean Coal Technology

\section{Introduction}

It is well known that energy utilization plays an important role in the progress of industry and civilization. The employment of coal rose in a significant way for the purpose of obtaining heat and power. However, burning coal has caused numerous serious air pollution problems; it has also emitted a tremendous amount of carbon dioxide. Currently, on account of the remarkable fluctuations in an increase in global temperatures, people are acutely aware of the importance of reducing $\mathrm{CO}_{2}$ emissions. Furthermore, it has been reported that reserves of oil and natural gas may last for only 40-60 years longer [1]. In contrast, coal reserves have been available for over one hundred years and its price is relatively lower than oil and natural gas. For these reasons, while coal is consumed as an essential energy resource, how to utilize it in a cleaner way has become an important task.

Conventionally, most coal is pulverized and consumed via direct combustion in large-scale utility furnaces for generating electricity [2]. This method benefits from well-developed techniques and knowledge, but its efficiency is still relatively low. Over the years, the development of clean coal technology (CCT) has drawn much attention [3].

[DOI: 10.1299/jtst 8.190 ]

Copyright $\odot 2013$ by JSME 
Gasification plays a key role in carrying out CCT where coal is converted into syngas (i.e. $\mathrm{CO}+\mathrm{H}_{2}$ ), the main component of the product gas, in an oxygen deficient environment [4]. Moreover, co-gasification of biomass with coal, which is considered a bridge between energy production systems based on fossil fuels and those based on renewable energy sources, could contribute to reducing $\mathrm{CO}_{2}$ emissions. On the other hand, biomass has a lower ash and sulphur content than coal, a higher volatile matter yield, and fixed carbon with higher reactivity. Therefore, co-gasification makes feasible biomass gasification on a larger scale and thereby with higher efficiency [5].

Gasification is a very complex thermal conversion process. The result of gasification is influenced by many factors, such as the geometry of the gasifier, feed types, the oxygen-to-fuel ratio (O/F ratio), and gasifier temperature among others. However, when the number of factors and levels in each factor increases, application of a full factorial design is very time consuming, expensive and sometimes impossible. Therefore, to minimize the number of tests required, the Taguchi method was developed in 1990 [6]. The Taguchi method simplifies the design of an experiment by developing a set of fractional factorial designs that can be used as templates and which greatly streamline the experimental process [7]. To date, the Taguchi method has been widely and successfully applied for the optimum process parameters in various subject areas such as aerospace [8], environment [9], materials manufacturing [10], milling [11], welding [12], and mechanical engineering [13].

Some energy literature has incorporated the Taguchi method. $\mathrm{Wu}$ and $\mathrm{Ku}$ [14] focused on the optimal parameters estimation for rectangular cylinders in PEM fuel cells (PEMFC) and found that five rectangular cylinders are the optimal geometry. Through the Taguchi method, they found that the cell temperature, the hydrogen and oxygen stoichiometric flow ratio, and the interaction of the anode and cathode humidification temperature are the significant factors of the PEMFC. Further, they applied the Taguchi method to analyze the transport phenomenon of PEMFC in following year [15]. Their results indicated that the primary optimal combination factor is a cell temperature of $333 \mathrm{~K}$, an anode humidification temperature of $333 \mathrm{~K}$, a cathode humidification temperature of $313 \mathrm{~K}$, a hydrogen stoichiometric flow ratio of 1.2, and an oxygen stoichiometric flow ratio of 1.2 to maximizing electrical power and minimizing pressure drops. Chary and Dastidar [16] used the Taguchi method to investigate a different set of process variables in oil agglomeration and suggested that the particle size of coal is the major influence on agglomerate yield. They showed that the optimized conditions are low ash high sulphur coal, Karanja oil, $+75-200 \mu \mathrm{m}$ and 3\% pulp density. Paek and Kim [17] used the Taguchi method to analyze various significant parameters of the low-rank coal grinding process, which involved a hammer mill and prepared coal for the KBR transport gasifier. Their results indicated that the best aperture size for the screen in the second hammer mill was $1.3 \mathrm{~mm}$, and low-rank coal with low moisture content was best for hammer grinding.

In examining the literature published recently, a number of studies for gasification have been implemented. However, no application of the Taguchi method to gasification studies has been reported until the present time owing to the many combinations with numerous experiments, which leads to requiring too much time and money. The Taguchi method seems to be of great use for gasification studies in which many potential affecting factors with different levels exist. Therefore, the present study was conducted to optimize the gasification process in an entrained-flow gasifier through the application of the Taguchi method in conjunction with a simulation method. From these predictions, the obtained results will be adopted as potential measures to enhance the productivity of gasifiers in the future.

\section{Numerical method}

\subsection{Geometry of reactor}

Fuel gasification in an entrained-flow gasifier is explored in the present study, the 
geometry of which is sketched in Fig. 1a. It is a dry feed, pressurized entrained-flow gasifier with a capacity of two metric tons per day [18] and a height and diameter of 5,151.2 and $270.3 \mathrm{~mm}$, respectively. The inlet configuration consists of a center inlet and a concentric ring inlet as show in Fig. 1b. Fuel and carrier gas are sent into the gasifier from the center inlet, whereas oxygen is transported from the concentric ring inlet. The distance from the oxygen inlet to the gasifier centerline is $45 \mathrm{~mm}$. The diameter of the center inlet and the width of the concentric ring inlet are 20 and $5 \mathrm{~mm}$, respectively.

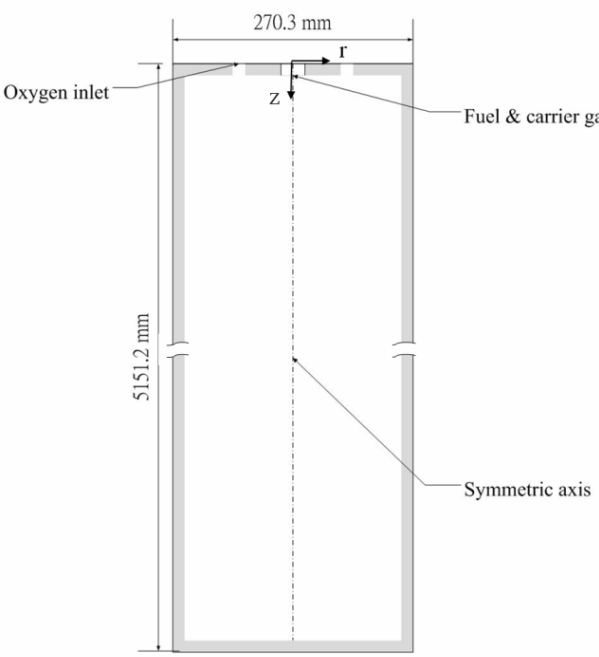

(a)

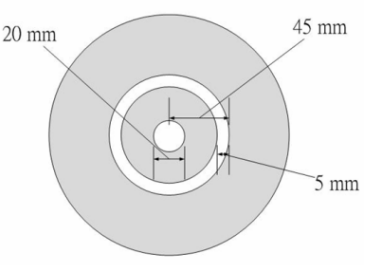

(b)

Fig. 1. Schematics of (a) the entrained-flow gasifier and (b) the top view of the gasifier inlet.

\subsection{Assumptions and governing equations}

Fuel reactions in a gasifier are related to fluid dynamics, heat and mass transfers, and chemical reactions. To make the physical problem more tractable, the following assumptions are included (1) A steady, axisymmetric, incompressible, and turbulent flow field is adopted, (2) Thermal radiation and body force of the flow in the gasifier are ignored, (3) The formation of air pollutants from gasification, such as $\mathrm{NH}_{3}, \mathrm{HCN}, \mathrm{H}_{2} \mathrm{~S}, \mathrm{CS}_{2}$, and COS, are neglected, and (4) The wall of the gasifier is uniform. Because of the assumption of axisymmetric flow, the three-dimensional gasifier can be reduced to a two-dimensional reactor in the simulation. Therefore, the steady-state, time-averaged, Navier-Stokes, energy and species equations are solved. The governing equations are given below.

$$
\begin{aligned}
& \frac{\partial}{\partial x_{i}}\left(\rho u_{i j}\right)=\frac{\Delta m_{p}}{m_{p, 0}} \dot{m}_{p, 0} \\
& \frac{\partial}{\partial x_{i}}\left(\rho u_{i} u_{j}\right)=-\frac{\partial p}{\partial x_{j}}+\frac{\partial}{\partial x_{i}}\left(\tau_{i j}-\rho \overline{u_{i}^{\prime} u_{j}^{\prime}}\right)+\sum\left[\frac{18 \mu C_{D} \operatorname{Re}}{\rho_{p} d_{p}^{2} 24}\left(u_{p}-u\right)\right] \dot{m}_{p} \Delta t \\
& \frac{\partial}{\partial x_{i}}\left(\rho c_{p} u_{i} T\right)=\frac{\partial}{\partial x_{i}}\left(\lambda \frac{\partial T}{\partial x_{i}}-\rho c_{p} \overline{u_{i}^{\prime} T^{\prime}}\right)-\sum_{j} \frac{\Delta H_{j}^{0}}{M_{j}} \bar{R}_{j} \\
& \frac{\partial}{\partial x_{i}}\left(\rho u_{i} Y_{j}\right)=\frac{\partial}{\partial x_{i}}\left(\rho D \frac{\partial Y_{j}}{\partial x_{i}}-\rho \overline{u_{i}^{\prime} Y_{j}^{\prime}}\right)+S_{r}+\bar{R}_{i}
\end{aligned}
$$

where $\tau_{i j}$ is the symmetric stress tensor and $-\rho \overline{u_{i}^{\prime} u_{j}^{\prime}}$ is the Reynolds stress. The standard $k-\varepsilon$ turbulence model is also employed to solve the turbulent flow. The turbulence kinematic viscosity is calculated by: 


$$
\mu_{t}=\rho C_{\mu} k^{2} / \varepsilon
$$

where $C_{\mu}$ is the viscosity constant, $k$ the turbulence kinetic energy and $\varepsilon$ the turbulence dissipation rate. $k$ and $\varepsilon$ are calculated from the following transport equations:

$$
\begin{aligned}
& \frac{\partial}{\partial x_{i}}\left(\rho u_{i} k\right)=\frac{\partial}{\partial x_{i}}\left[\left(\mu+\frac{\mu_{t}}{\sigma_{k}}\right) \frac{\partial k}{\partial x_{i}}\right]+G_{k}-\rho \varepsilon \\
& \frac{\partial}{\partial x_{i}}\left(\rho u_{i} \varepsilon\right)=\frac{\partial}{\partial x_{i}}\left[\left(\mu+\frac{\mu_{t}}{\sigma_{\varepsilon}}\right) \frac{\partial \varepsilon}{\partial x_{i}}\right]+C_{1 \varepsilon} G_{k} \frac{\varepsilon}{k}-C_{2 \varepsilon} G_{k} \rho \frac{\varepsilon^{2}}{k}
\end{aligned}
$$

where $G_{k}$ is the generation of turbulence kinetic energy due to mean velocity gradients. The constants in the transport equations are selected from Launder and Spalding [19] and they are given by $C_{\mu}=0.09, C_{1 \varepsilon}=1.44, C_{2 \varepsilon}=1.92, \sigma_{k}=1.0$ and $\sigma_{\varepsilon}=1.3$. The turbulence heat conductivity $(\lambda)$ and diffusion coefficient $(D)$ in Eqs. (3) and (4) are rewritten as:

$$
\begin{gathered}
\rho c_{p} \overline{u_{i}^{\prime} T^{\prime}}=-\lambda \frac{\partial T}{\partial x_{i}}=-c_{p} \frac{\mu_{t}}{\operatorname{Pr}_{t}} \frac{\partial T}{\partial x_{i}} \\
\rho \overline{u_{i}^{\prime} Y_{j}^{\prime}}=-\rho D \frac{\partial Y}{\partial x_{i}}=-\frac{\mu_{t}}{S c_{t}} \frac{\partial Y}{\partial x_{i}}
\end{gathered}
$$

where $\operatorname{Pr}_{t}(=0.85)$ is the turbulence Prandtl number and $S c_{t}(=0.7)$ is the turbulence Schmidt number.

The behavior of fuel particles in fluid is modeled by a Eulerian-Lagrangian approach which considers the inertia and hydrodynamic drags coupled to mass, energy, and momentum transport from the particles into the fluid. A discrete-phase-model (DPM) is employed to track the trajectories of fuel particles through the continuous fluid phase. In this model, the trajectories of coal particles are tracked when they move through the continuous phase of the fluid [20]. The interaction between the discrete phase and the continuous phase is also taken into account by treating the heat and mass losses of the particles as the source terms in the governing equations.

\subsection{Chemical reactions}

While coal gasification takes place in a high temperature environment, the coal is decomposed into volatiles, char and ash. The compositions released from the coal can be expressed by the following equilibrium equation [21].

$$
\begin{aligned}
& \text { Fuel } \rightarrow \\
& \alpha_{1} \mathrm{CH}_{4}+\alpha_{2} \mathrm{H}_{2}+\alpha_{3} \mathrm{CO}+\alpha_{4} \mathrm{CO}_{2}+\alpha_{5} \mathrm{H}_{2} \mathrm{O}+\alpha_{6} \mathrm{Char}+\alpha_{7} \mathrm{Ash} \\
& \left(\sum_{i} \alpha_{i}=1\right)
\end{aligned}
$$

Considering the devolatilization process which dominates fuel reactions in the initial injection period [22], volatile release is described by a two-step devolatilization model [23] as given in the following:

$$
\begin{array}{ll}
\text { Fuel } \stackrel{k_{\iota}}{\longrightarrow}\left(1-Y_{l}\right) \times \text { Char }_{l}+Y_{l} \times \text { Volatile } & \text { (for low temperature) } \\
\text { Fuel } \stackrel{k_{h}}{\longrightarrow}\left(1-Y_{h}\right) \times \text { Char }_{h}+Y_{h} \times \text { Volatile } & \text { (for high temperature) }
\end{array}
$$

where $Y$ denotes the stoichiometric coefficient. When the temperature is relatively low, the reaction is dominated by Eq. (11); but is dominated by Eq. (12) if the temperature is relatively high. Consequently, the reaction kinetics of volatiles can be expressed by:

$$
\begin{aligned}
& \frac{d V}{d t}=\left(k_{l} Y_{l}+k_{h} Y_{h}\right) \text { Fuel } \\
& k_{l}=A_{l} \exp \left(-E_{a, l} / R T_{P}\right) \\
& k_{h}=A_{h} \exp \left(-E_{a, h} / R T_{P}\right)
\end{aligned}
$$

where $V$ is the mass fraction of volatiles, $k$ the reaction rate constant, $A$ the 
pre-exponential factor, $T_{P}$ the fuel particle temperature, and $E_{a}$ the activation energy of the reaction. The values of $Y_{l}, k_{l}, Y_{h}, k_{h}, E_{l}$, and $E_{h}$ are listed in Table 1 [23].

Table 1 Kinetic parameters of reactions.

\begin{tabular}{|c|c|c|c|}
\hline \multicolumn{4}{|l|}{ Devolatilization } \\
\hline$Y_{l}$ & 0.3 & & \\
\hline$Y_{h}$ & 1 & & \\
\hline$k_{l}\left(\mathrm{~s}^{-1}\right)$ & 200,000 & & \\
\hline$k_{h}\left(\mathrm{~s}^{-1}\right)$ & $1.3 \times 10^{7}$ & & \\
\hline$E_{l}\left(\mathrm{~J} \mathrm{kmol}^{-1}\right)$ & 104.6 & & \\
\hline$E_{h}\left(\mathrm{~J} \mathrm{kmol}^{-1}\right)$ & 167.4 & & \\
\hline \multicolumn{4}{|l|}{ Gasification } \\
\hline $\begin{array}{l}k_{f} \\
\left(\mathrm{kmol}^{1-\mathrm{m}} \mathrm{m}^{3 \mathrm{~m}-3} \mathrm{~s}^{-1}\right)\end{array}$ & $\begin{array}{l}A \\
\left(\mathrm{kmol}^{1-\mathrm{m}} \mathrm{K}^{-\mathrm{B}} \mathrm{m}^{3 \mathrm{~m}-3} \mathrm{~s}^{-1}\right)\end{array}$ & $B$ & $\begin{array}{l}E_{a} \\
\left(\mathrm{~J} \mathrm{kmol}^{-1}\right)\end{array}$ \\
\hline$k_{1}$ & 0.002 & 0 & $7.9 \times 10^{7}$ \\
\hline$k_{2}$ & 242 & 0 & $2.75 \times 10^{8}$ \\
\hline$k_{3}$ & 426 & 0 & $3.16 \times 10^{8}$ \\
\hline$k_{4}$ & $5 \times 10^{10}$ & 0 & $1.68 \times 10^{8}$ \\
\hline$k_{5}$ & $2.2 \times 10^{20}$ & 0 & $1.67 \times 10^{6}$ \\
\hline$k_{6}$ & $2.6 \times 10^{10}$ & 0 & $8.4 \times 10^{8}$ \\
\hline$k_{7}$ & 4,000 & -1 & $1.26 \times 10^{6}$ \\
\hline$k_{8}$ & 4,400 & 0 & $1.68 \times 10^{8}$ \\
\hline
\end{tabular}

When char is produced from coal devolatilization, $\mathrm{CO}$ and $\mathrm{H}_{2}$ can be generated from char gasification. Char gasification is formed by the following equations [24]

$$
\begin{array}{ll}
\mathrm{C}+1 / 2 \mathrm{O}_{2} \stackrel{k_{1}}{\longrightarrow} \mathrm{CO} & \Delta H^{0}=-111 \mathrm{MJ} \mathrm{kmol}^{-1} \\
\mathrm{C}+\mathrm{CO}_{2} \stackrel{k_{2}}{\longrightarrow} 2 \mathrm{CO} & \Delta H^{0}=+172 \mathrm{MJ} \mathrm{kmol}^{-1} \\
\mathrm{C}+\mathrm{H}_{2} \mathrm{O} \stackrel{k_{3}}{\longrightarrow} \mathrm{CO}+\mathrm{H}_{2} & \Delta H^{0}=+131 \mathrm{MJ} \mathrm{kmol}^{-1}
\end{array}
$$

where $\Delta H^{0}$ is the heat of reaction at the standard state (i.e. $298 \mathrm{~K}$ and $1 \mathrm{~atm}$ ). Clearly, Eq. (16) is an exothermic reaction, whereas Eqs. (17) and (18) are endothermic ones. With regard to gas-phase chemical reactions, the relevant equations include [25]

$$
\begin{array}{ll}
\mathrm{H}_{2}+1 / 2 \mathrm{O}_{2} \stackrel{k_{4}}{\longrightarrow} \mathrm{H}_{2} \mathrm{O} & \Delta H^{0}=-242 \mathrm{MJ} \mathrm{kmol}^{-1} \\
\mathrm{CO}+1 / 2 \mathrm{O}_{2} \stackrel{k_{5}}{\longrightarrow} \mathrm{CO}_{2} & \Delta H^{0}=-283 \mathrm{MJ} \mathrm{kmol}^{-1} \\
\mathrm{CO}+\mathrm{H}_{2} \mathrm{O} \stackrel{k_{6}}{\longrightarrow} \mathrm{CO}_{2}+H_{2} & \Delta H^{0}=-41.1 \mathrm{MJ} \mathrm{kmol}^{-1} \\
\mathrm{CH}_{4}+1 / 2 \mathrm{O}_{2} \stackrel{k_{7}}{\longrightarrow} \mathrm{CO}+2 \mathrm{H}_{2} & \Delta H^{0}=-35.7 \mathrm{MJ} \mathrm{kmol}^{-1} \\
\mathrm{CH}_{4}+\mathrm{H}_{2} \mathrm{O} \stackrel{k_{8}}{\longrightarrow} \mathrm{CO}+3 \mathrm{H}_{2} & \Delta H^{0}=+206 \mathrm{MJ} \mathrm{kmol}^{-1}
\end{array}
$$

In the species equation, $S_{r}$ is the summation of various species reaction rates and can be expressed as:

$$
\begin{aligned}
& S_{r}=\sum_{j=1}^{N_{r}} M_{j, r} w_{j, r} \\
& w_{j, r}=\left(v_{j, r}^{\prime \prime}-v_{j, r}^{\prime}\right) k_{f}\left(\prod_{i=1}^{N_{r}} C_{i}^{\eta^{\prime}}-\frac{1}{K_{e q}} \prod_{i=1}^{N_{r}} C_{i}^{\eta^{\prime \prime}}\right) \\
& k_{f}=A T^{B} e^{-E_{a} / R T}
\end{aligned}
$$

In the above equation, the forward reaction rate constant $k_{f}$ is established based on the 
Arrhenius law, where $A$ is the pre-exponential factor and $B$ is the temperature exponent. Their values in various chemical reactions are listed in Table 1 as well.

\subsection{Boundary conditions, feed properties and control parameters}

The fuel at $300 \mathrm{~K}$ was fed into the gasifier from the top of the reactor, while a carrier gas (i.e. air) at $300 \mathrm{~K}$ was employed to aid in transporting the fuel particles. Their mass flow rates were controlled at 0.023 and $0.025 \mathrm{~kg} \mathrm{~s}^{-1}$, respectively. The sizes of fuel particles were in the range of $44-250 \mu \mathrm{m}$, with an average particle size of $103 \mu \mathrm{m}$, as determined by the Rosin-Rammler distribution function [26]. Oxygen was used as the oxidant. The centerline of the gasifier was an axisymmetric line so that no heat or mass fluxes passed through the line. The wall of the gasifier was conceived as an adiabatic wall and no slip conditions were obeyed.

Two different fuels, bamboo [27] and high-volatile bituminous coal [28], served as the basis of this study. Properties of the fuels, such as proximate, elemental analyses and boundary conditions are summarized in Table 2. Ultimately, the objective of this study was to select the optimization control parameters of the gasification process in an entrained-flow gasifier. Based on the analysis of this study, four control parameter factors and three levels for each factor were selected, as shown in Table 2. These factors and levels were selected based on the available literatures [29-32].

Table 2 Proximate, elemental analyses of fuels and factors, levels of control parameters.

\begin{tabular}{|c|c|c|c|c|}
\hline \multicolumn{5}{|c|}{ Fuels property } \\
\hline & & & Bamboo & Coal \\
\hline \multicolumn{5}{|c|}{ Proximate analysis (wt\%, dry basis) } \\
\hline \multicolumn{3}{|c|}{$\mathrm{VM}$} & 80.13 & 34.86 \\
\hline \multicolumn{3}{|l|}{$\mathrm{FC}$} & 17.75 & 58.92 \\
\hline \multicolumn{3}{|l|}{ Ash } & 2.12 & 6.22 \\
\hline \multicolumn{5}{|c|}{ Elemental analysis (wt\%, dry basis) } \\
\hline \multicolumn{3}{|c|}{$\mathrm{C}$} & 46.78 & 67.71 \\
\hline \multicolumn{3}{|l|}{$\mathrm{H}$} & 6.38 & 4.95 \\
\hline \multicolumn{3}{|l|}{$\mathrm{N}$} & 0.25 & 1.18 \\
\hline \multicolumn{3}{|l|}{$\mathrm{O}$} & 46.59 & 26.16 \\
\hline \multicolumn{3}{|c|}{$\operatorname{HHV}\left(\mathrm{MJ} \mathrm{kg}^{-1}\right)$} & 18.75 & 26.22 \\
\hline \multicolumn{5}{|c|}{ Control parameters } \\
\hline factors & Illustrate & Level 1 & Level 2 & Level 3 \\
\hline A & Wall temperature $(\mathrm{K})$ & 1500 & 1700 & 1900 \\
\hline B & $\mathrm{O} / \mathrm{F}$ ratio & 1.2 & 0.9 & 0.6 \\
\hline \multirow[t]{2}{*}{$\mathrm{C}$} & Type of feed & Bamboo & Coal $80 \%$ & Coal \\
\hline & & & \multicolumn{2}{|c|}{ Bamboo 20\% } \\
\hline $\mathrm{D}$ & Pressure (MPa) & 1 & 2 & 3 \\
\hline
\end{tabular}

\subsection{Parameters and performance indices}

From an engineering standpoint, concern arises when the functional characteristics of a product deviate from the desired target values. Unlike the engineering standpoint, Taguchi method theory is derived from loss functions in statistics. The loss function, which is continuous, is measured by the deflection from the target value, as shown in Fig. 2. Product 
performance begins to suffer when the design parameters deviate from the target value. This loss function takes the following basic quadratic form:

$$
L(y)=K(y-T)^{2}
$$

where $\mathrm{L}$ is the loss, $\mathrm{K}$ is a constant that depends on the magnitude of the characteristic, $\mathrm{T}$ is the target response, and $\mathrm{y}$ is the measured response.

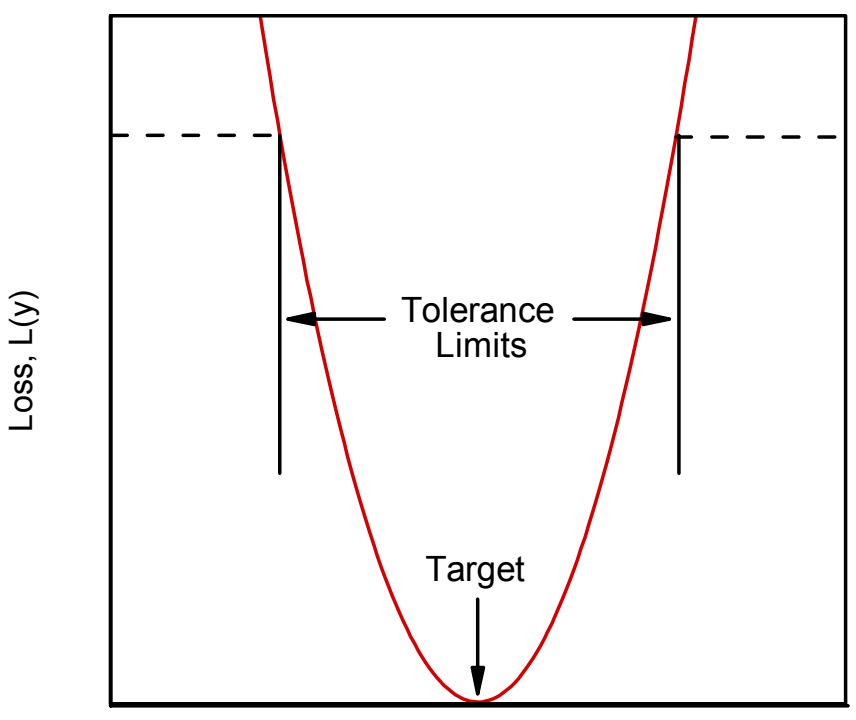

Response, y

Fig. 2. Taguchi Loss Function [6].

The advantage of the Taguchi method is its ease of use and emphasis on reducing variability to give a more economical production. The focus of the Taguchi method is to make the process or product insensitive to those sources of variation. Analysis of the signal-to-noise ratio ( $\mathrm{S} / \mathrm{N}$ ratio) was subsequently used to evaluate the result. The Taguchi method defines three different forms of $\mathrm{S} / \mathrm{N}$ ratio including the nominal-the-better (NB), the larger-the-better (LB) and the smaller-the-better (SB). Regardless of the category of performance characteristics, a larger $\mathrm{S} / \mathrm{N}$ ratio corresponds to a better performance characteristic. Moreover, it is known that the cold gas efficiency (CGE) is an important index in accounting for the performance of coal gasification. It is defined as follows [33]

$$
C G E(\%)=\frac{\dot{m}_{\text {out }}\left(y_{\mathrm{H}_{2}} H H V_{\mathrm{H}_{2}}+y_{C O} H H V_{C O}+y_{\mathrm{CH}_{4}} H H V_{\mathrm{CH}_{4}}\right)}{\dot{m}_{\text {in,fuel }} H H V_{\text {fuel }}} \times 100
$$

where $y_{i}$ is the mass fraction of species $i$ in the product gas. That is, CGE is determined from the concentrations of $\mathrm{H}_{2}, \mathrm{CO}$, and $\mathrm{CH}_{4}$. Thus, $\mathrm{CGE}$ is selected as the evaluation criteria for the $\mathrm{S} / \mathrm{N}$ ratio of static characteristics in this study. A higher value of $\mathrm{CGE}$ (optimum value $=100$ ) means that the performance of gasification is better. Hence, the $\mathrm{S} / \mathrm{N}$ ratio of the nominal-the-better $(\mathrm{NB})$ is selected for this study. The $\mathrm{S} / \mathrm{N}$ ratio was calculated using the following formula [6]:

$$
S / N=-10 \log \left[(y-T)^{2}\right]
$$

where, $T$ is the target value of the quality characteristics. This place, $T$ means the highest value of the CGE and the value of $T$ equals one hundred, while $y$ represents the measured results. Here, $y$ is the amount of CGE obtained from each gasification simulation case. 


\section{Results and Discussion}

This study used the commercial software ANSYS FLUENT V12 to simulate the coal and biomass gasification phenomena. In the simulations, the SIMPLE algorithm was utilized to solve the governing equations in association with the boundary conditions. The second-order upwind scheme was employed to calculate the convection and diffusion fluxes. Two different fuels, bamboo and high-volatile bituminous coal, served as the basis of this study. The properties of the fuels, such as proximate, elemental, and calorific analyses, are summarized in Table 2. On the other hand, several factors, such as the wall temperature, $\mathrm{O} / \mathrm{F}$ ratio, feed type and pressure were controlled between three different levels. The effects of several factors on the gasification process can be analyzed by the Taguchi method.

\subsection{Validation}

To seek a proper grid system for predicting the phenomena, four different grid systems comprising 8,800, 17,600, 35,200 and 70,400 were tested and compared with each other. Fig. 3 displays the temperature distribution at the exit of the gasifier. In the test, only air $(300 \mathrm{~K})$ with a flow rate of $0.025 \mathrm{~kg} \mathrm{~s}^{-1}$ was sent into the reactor. The wall temperature was $1700 \mathrm{~K}$ and the pressure was $2 \mathrm{MPa}$. It can be seen that the temperature profile of the third grid system is close to that of the fourth. This implies that the third grid system can satisfy the requirement of grid independence, and was thus used for simulations. Moreover, solid tests for the validation of chemical kinetics (Table 1) have been carried out in a previous study [34] where the numerical predictions were in good agreement with the experimental results.

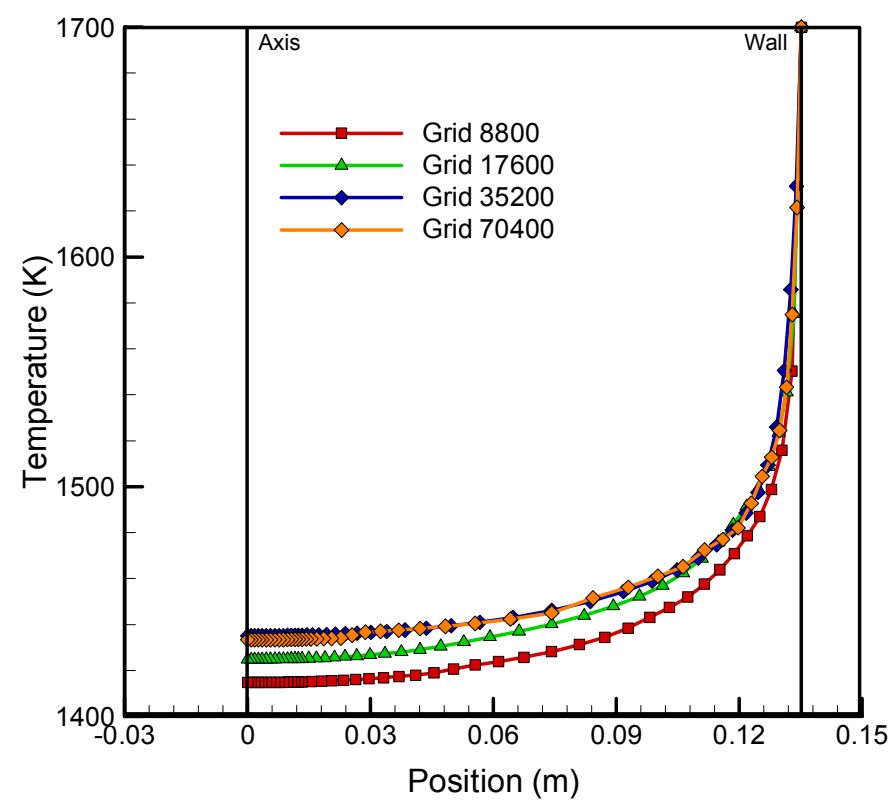

Fig. 3. Temperature distributions at the exit of the gasifier under various grid systems.

\subsection{Parameters analysis by the Taguchi method}

The experiment design of the Taguchi method is based on a matrix where the columns are assigned to the factors and the rows list the experimental conditions for each case. Once the properties (i.e. levels) and parameters (i.e. control conditions) to be investigated have been chosen, the next step is to define the experiment. This is done by selecting an 
orthogonal array that uses an appropriate number of factors and levels to be investigated. In this study, an $\mathrm{L}_{9}\left(3^{4}\right)$ orthogonal array is used, as shown in Table 3, and is comprised of four factors and three levels for each factor. A full factorial approach would include a total of $\left(3^{4}\right)=81$ runs, but only nine designed cases are required for the Taguchi method. The calculation results of CGE are shown in Fig. 4a. The maximum value of CGE is $78.61 \%$ in Case 3, but a minimal value of $11.00 \%$ was found in Case 1 . The pronounced disparity in CGE reveals that different control conditions can clearly influence the gasification phenomenon. Around $67 \%$ of CGE can be improved if the operation of Case 1 is replaced by Case 3. Further, the profile of the $\mathrm{S} / \mathrm{N}$ ratio under different cases is presented in Fig. $4 \mathrm{~b}$, which shows that the trend in Figs. $4 \mathrm{a}$ and $4 \mathrm{~b}$ is similar. However, the effect of each control condition is difficult to estimate.

Table 3 The $\mathrm{L}_{9}\left(3^{4}\right)$ orthogonal array (Byrne and Taguchi,1986) [6].

\begin{tabular}{ccccc}
\hline Case & A & B & C & D \\
\hline 1 & 1 & 1 & 1 & 1 \\
2 & 1 & 2 & 2 & 2 \\
3 & 1 & 3 & 3 & 3 \\
4 & 2 & 1 & 2 & 3 \\
5 & 2 & 2 & 3 & 1 \\
6 & 2 & 3 & 1 & 2 \\
7 & 3 & 1 & 3 & 2 \\
8 & 3 & 2 & 1 & 3 \\
9 & 3 & 3 & 2 & 1 \\
\hline
\end{tabular}


(a)

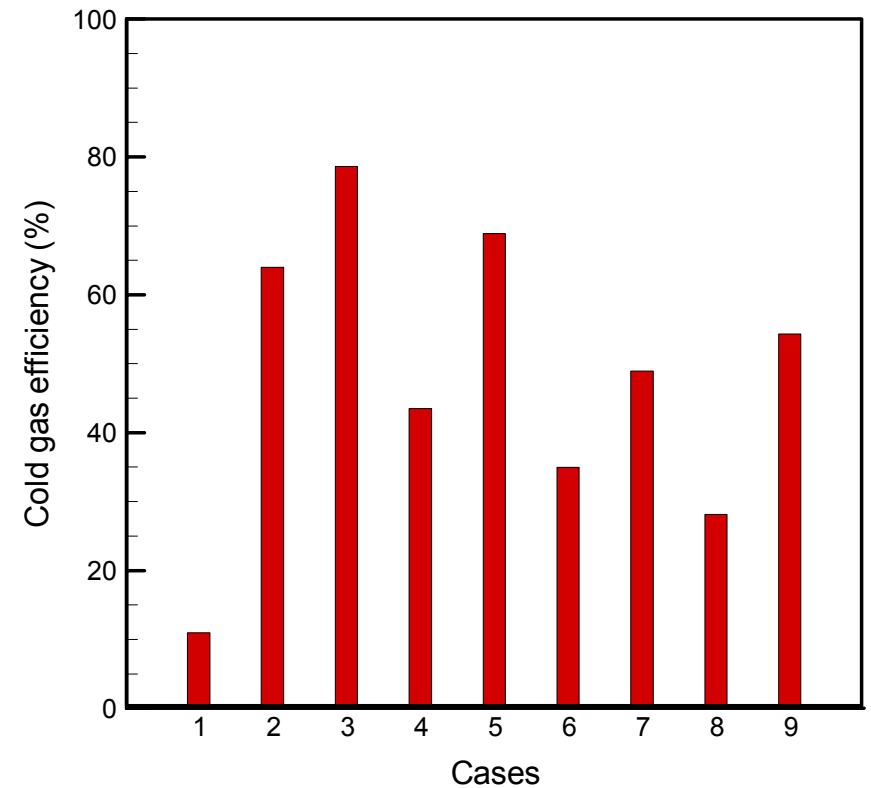

(b)

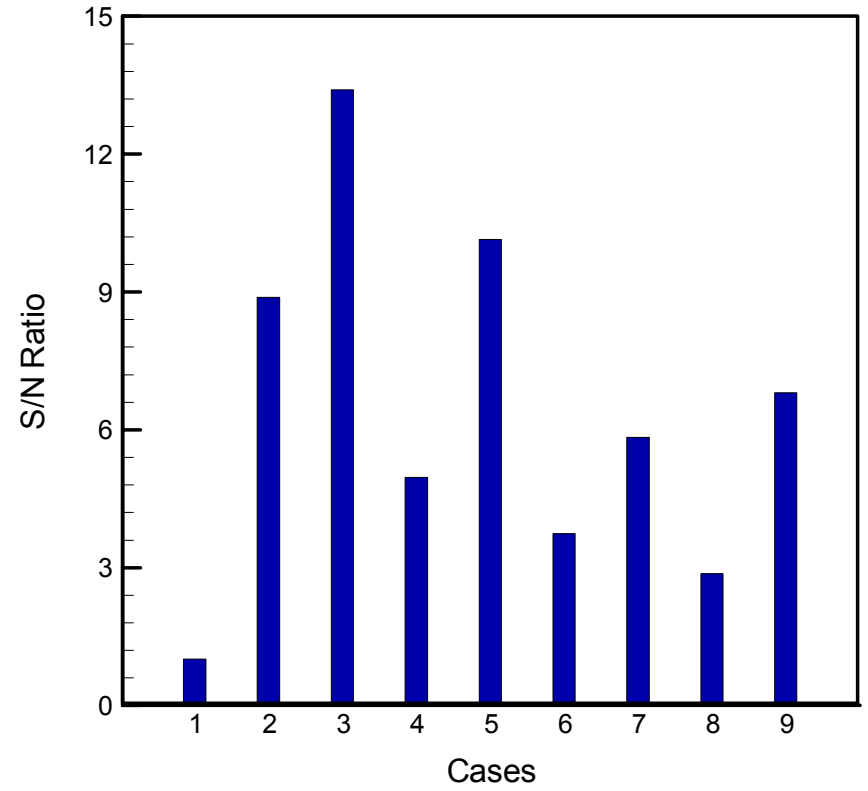

Fig. 4. Profiles of (a) cold gas efficiency and (b) $\mathrm{S} / \mathrm{N}$ ratio of different cases.

According to the results of Fig. 4b, the influence of each factor can be evaluated by the results of the $\mathrm{S} / \mathrm{N}$ ratio, as shown in Table 4. (i.e. The influence of factor $\mathrm{A}$ of Level 1 as shown in Table 4 is calculated by the mean value of the $\mathrm{S} / \mathrm{N}$ ratio from three Level 1 values of factor A in Fig $4 \mathrm{~b}$.) Results of each factor are obtained from the effects of the maximum level value minus the minimum level value, which are ranked. The effect values of A, B, C and $\mathrm{D}$ are $2.59,3.95,7.52$ and 1.09 , respectively. Overall, it can be seen that the influence strength order of each factor is $\mathrm{C}$ (feed type) $>\mathrm{B}(\mathrm{O} / \mathrm{F}$ ratio) $>\mathrm{A}$ (wall temperature) $>\mathrm{D}$ (pressure). The mean effect of the $\mathrm{S} / \mathrm{N}$ ratio is plotted in Fig. 5. Results show the variation of the $\mathrm{S} / \mathrm{N}$ ratio in the factor of each level. The maximum $\mathrm{S} / \mathrm{N}$ ratio of factor $\mathrm{A}$ appears as 7.76 in A1 (Level 1 of factor A), which others are displayed as B3 (7.98), C3 (9.79) and D3 
(7.08). Therefore, the optimized control conditions (A1B3C3D3) can be found when the results are summarized. This control condition is the same as the calculation result of Case 3 in the $\mathrm{L}_{9}\left(3^{4}\right)$ orthogonal array.

Table 4 Effect and rank of $\mathrm{S} / \mathrm{N}$ ratio for each factor.

\begin{tabular}{clllll}
\hline Factor & Level 1 & Level 2 & Level 3 & Effect & Rank \\
\hline A & 7.76 & 6.28 & 5.17 & 2.59 & 3 \\
B & 3.94 & 7.30 & 7.98 & 3.95 & 2 \\
C & 2.54 & 6.88 & 9.79 & 7.25 & 1 \\
D & 5.99 & 6.15 & 7.08 & 1.09 & 4 \\
\hline
\end{tabular}

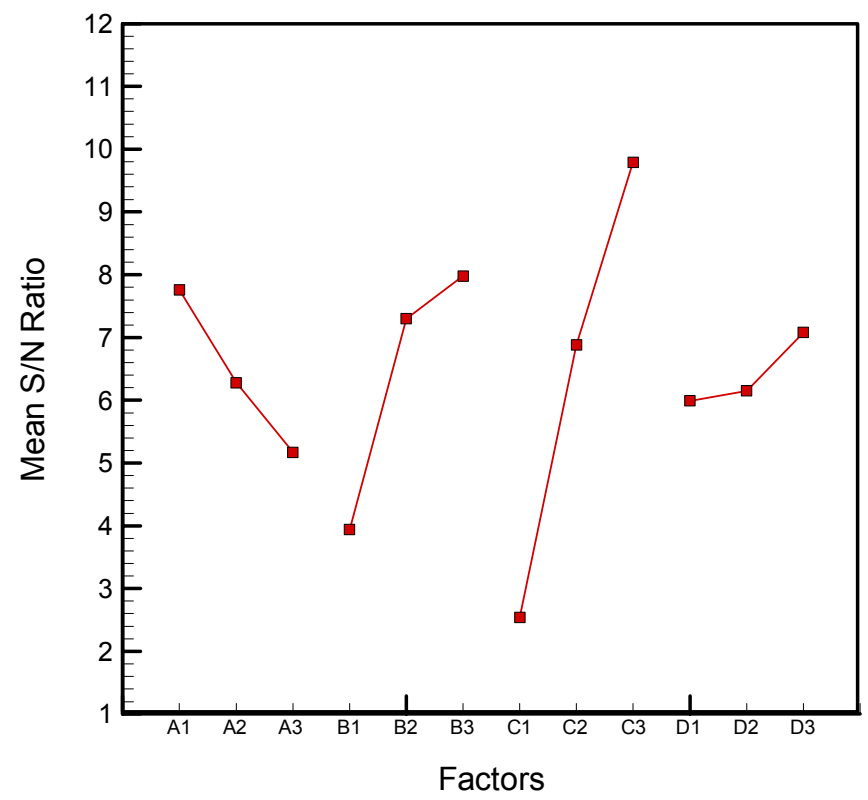

Fig. 5. The parameter effects on the mean $\mathrm{S} / \mathrm{N}$ ratio and factors for gasification process optimization.

\subsection{Optimum case compared with original cases}

The profiles of cold gas efficiency and $\mathrm{S} / \mathrm{N}$ ratio to original cases and the optimum case are presented in Fig. 6. The values of CGE for the case of Level 1, Level 2, Level 3, and the optimum are $11.00 \%, 64.35 \%, 77.83 \%$, and $78.61 \%$, respectively. Corresponding to these values, the $\mathrm{S} / \mathrm{N}$ ratios are $1.01,8.96,13.09$, and 13.40 , respectively. For the result of Level 1, which uses biomass feed, the feed type is the most influential factor making that CGE is very low. Contrary to the result of Level 1, the case for Level 3 has higher CGE because the feed type is coal. The optimum case also shows the same result. Fig. 7 demonstrates the isothermal contours in the gasifier. When the feed type is coal (Level 3), the maximum temperature is about $2400 \mathrm{~K}$. If the feed type is changed to bamboo $(20 \%)$ mixed with coal $(80 \%)$ (Level 2), the maximum temperature can reach $2320 \mathrm{~K}$. Once the feed type is changed to the bamboo (Level 1), the maximum temperature substantially lowers to about $1300 \mathrm{~K}$. This difference is attributed to the higher heating value (HHV) of coal at 26.22 MJ $\mathrm{kg}^{-1}$, which is much higher than bamboo $\left(18.75 \mathrm{MJ} \mathrm{kg}^{-1}\right)$. Therefore, this is the reason why 
the optimum case uses coal as the feed. By contrast, the highest downstream temperature distribution is about $1420 \mathrm{~K}$ when the feed is bamboo (Level 1). This arises from the fact that the exothermic oxidation reactions are intensified with the higher $\mathrm{O} / \mathrm{F}$ ratio $(=1.2)$. If the $\mathrm{O} / \mathrm{F}$ ratio is decreased to 0.9 , a lower downstream temperature distribution is obtained (Level 2). Results of Level 3, show a lower downstream temperature distribution than Level 2 because the $\mathrm{O} / \mathrm{F}$ ratio is 0.6 . Comparing the optimum case with Level 3, the different temperature distribution appears in the wall position. This can be explained by the relatively lower wall temperature $(1500 \mathrm{~K})$ in the optimum case.

(a)

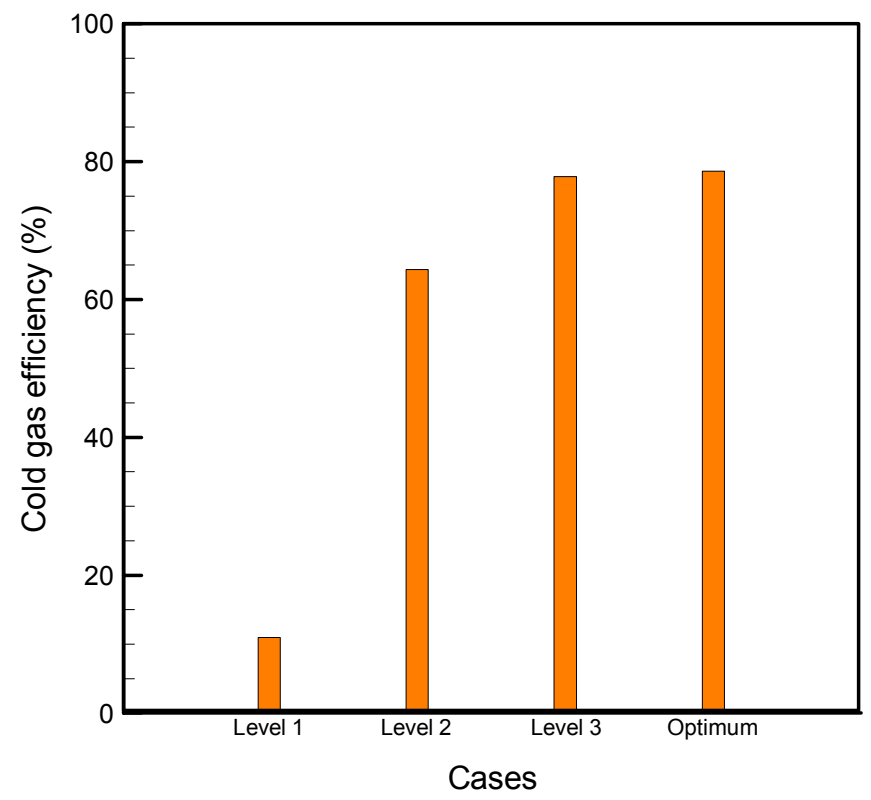

(b)

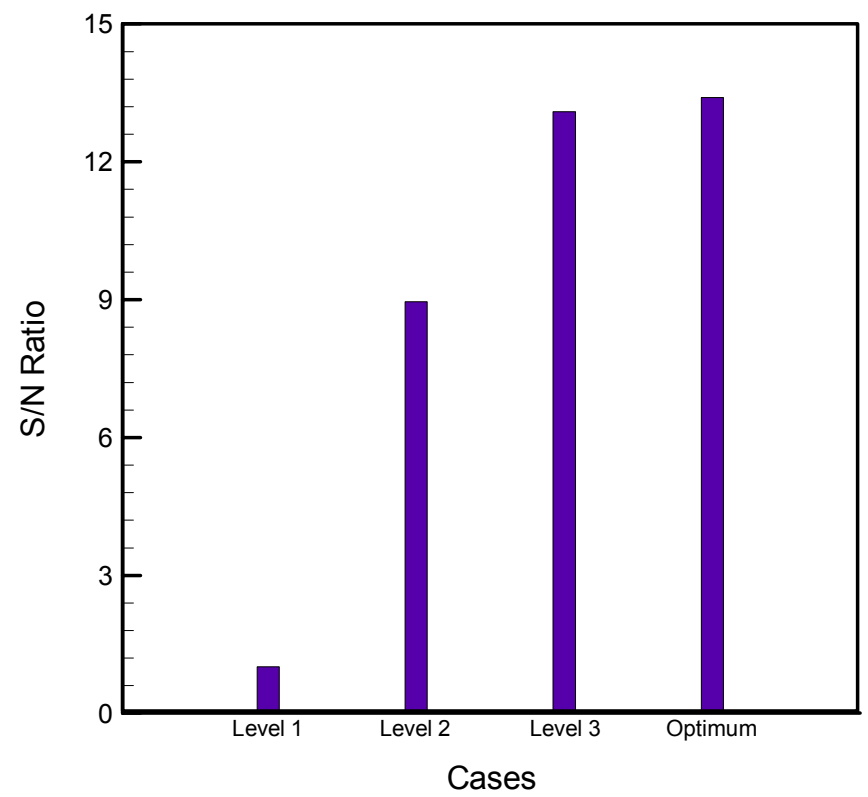

Fig. 6. Profiles of (a) cold gas efficiency and (b) $\mathrm{S} / \mathrm{N}$ ratio of optimum case compared with original cases. 


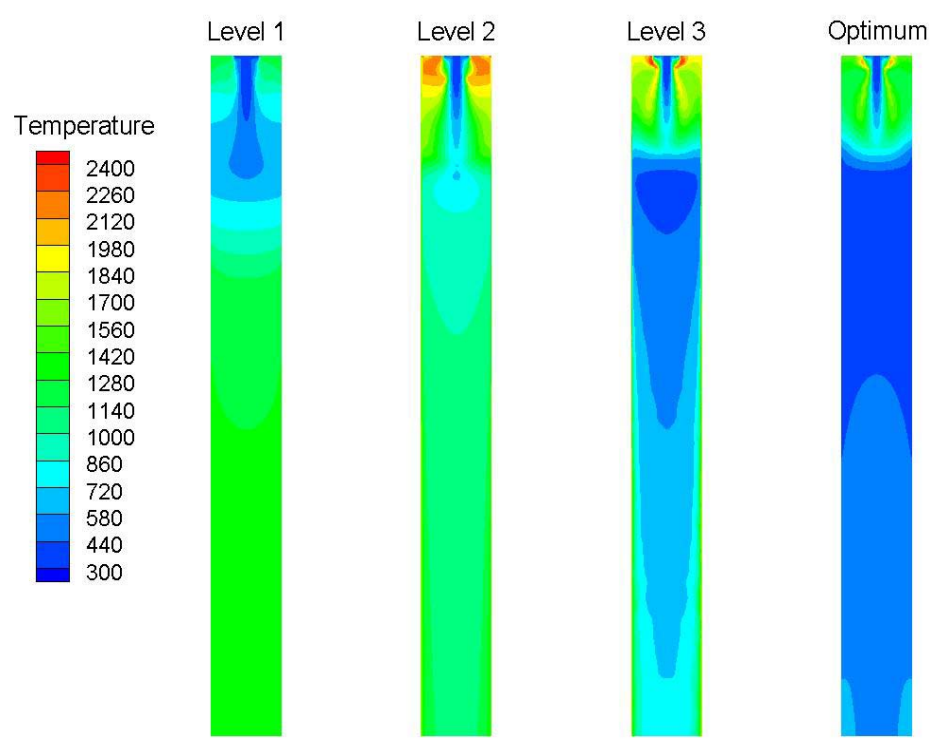

Fig. 7. Isothermal contours of original cases and optimum case.

The gas concentration profiles of $\mathrm{CO}, \mathrm{H}_{2}, \mathrm{CO}_{2}$, and $\mathrm{H}_{2} \mathrm{O}$ from the gasification of the original cases and the optimum case are plotted in Fig. 8. For bamboo gasification, it can be seen that the concentrations of $\mathrm{CO}_{2}$ and $\mathrm{H}_{2} \mathrm{O}$ are higher than those of $\mathrm{CO}$ and $\mathrm{H}_{2}$. This can be explained by the higher atomic $\mathrm{O} / \mathrm{C}$ and $\mathrm{H} / \mathrm{C}$ ratios in biomass which facilitate the formations of $\mathrm{CO}_{2}$ and $\mathrm{H}_{2} \mathrm{O}$. The formations of $\mathrm{CO}$ and $\mathrm{H}_{2}$ are enlarged to a certain extent in the case of Level 2. This means that bamboo mixed with coal can improve gasification performance. Overall, coal is the best feed of the three feed types because it has the highest HHV. Therefore, the optimizing results based on the Taguchi method are robust, which may improve the gasification process.

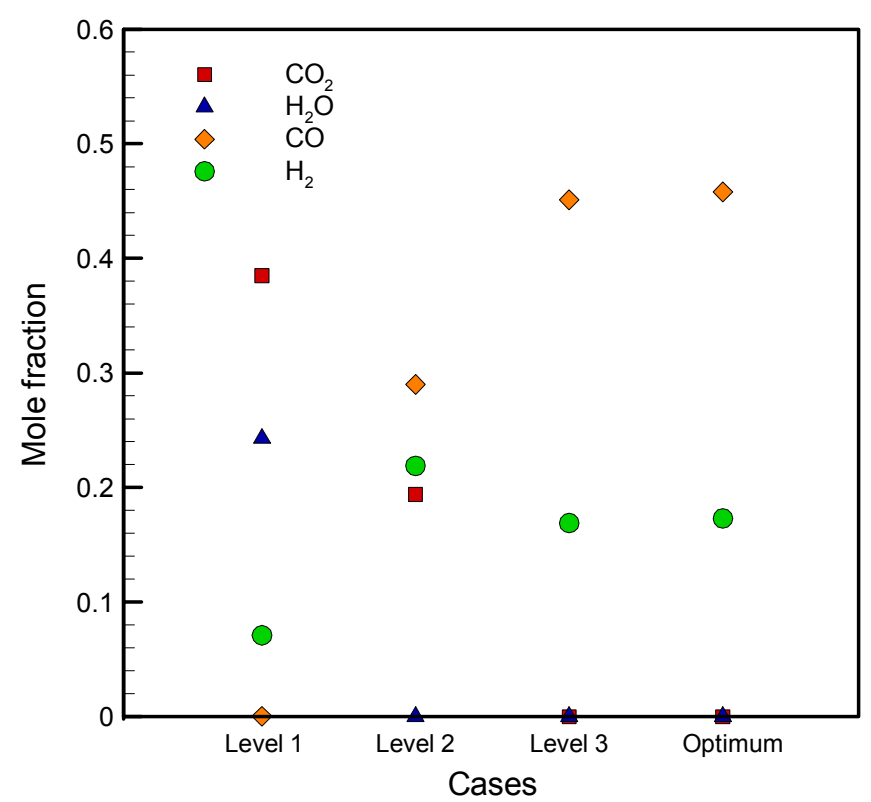

Fig. 8. Distributions of gas concentrations in the product gas from the gasification of original cases and the optimum case. 


\subsection{Gasification phenomena}

Fig. 9 presents the concentration (mole fraction) contours of $\mathrm{CO}$ and $\mathrm{H}_{2}$ in the gasifier. The formation of $\mathrm{CO}$ in the case of Level 3 is superior to that of Level 2 and Level 1. The reason is that the lower $\mathrm{O} / \mathrm{F}$ ratio hinders the combustion phenomenon to decrease the temperature. The behavior of higher $\mathrm{CO}$ concentration accompanied by the lower temperature is consistent with Vicente et al. [35]. Therefore, when the $\mathrm{O} / \mathrm{F}$ ratio is increased, the $\mathrm{CO}$ concentration is decreased gradually in the cases of Level 2 and Level 1. With respect to the influence of feed type, by virtue of a higher HHV and more carbon contained in the coal, the $\mathrm{CO}$ concentrations from the coal mixed with bamboo and pure coal gasification are further enlarged.

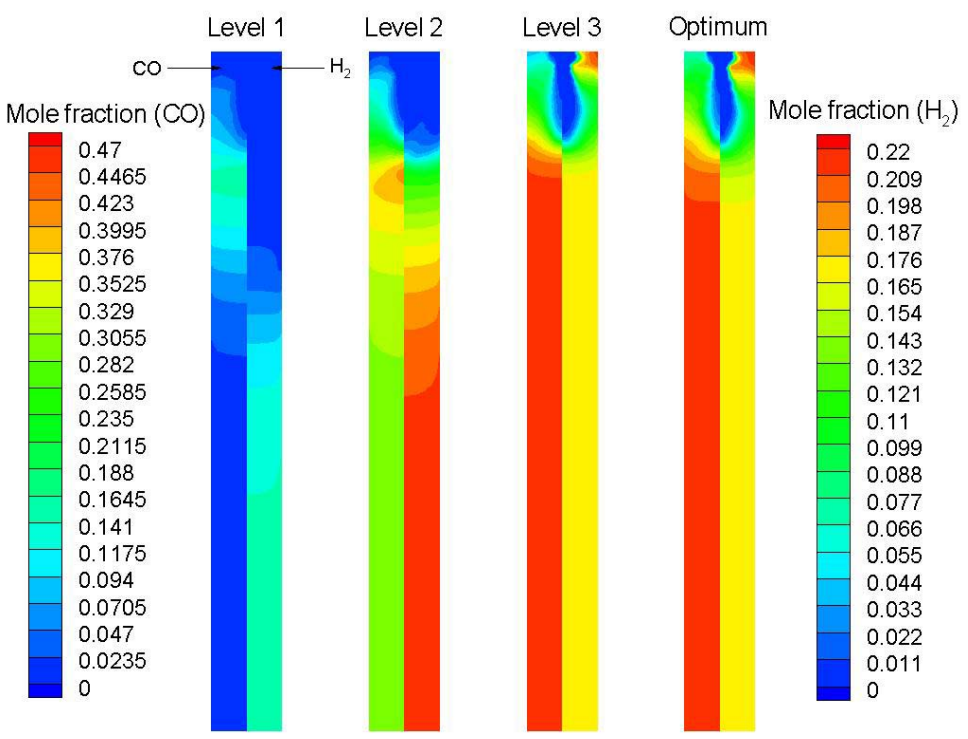

Fig. 9. Concentration profiles of $\mathrm{CO}$ and $\mathrm{H}_{2}$ of the gasification of original cases and the optimum case.

The distributions of $\mathrm{H}_{2} \mathrm{O}$ and $\mathrm{CO}_{2}$ are displayed in Fig. 10, which shows that the concentrations of $\mathrm{H}_{2} \mathrm{O}$ and $\mathrm{CO}_{2}$ from the gasification of bamboo are higher in Level 1. Figs. 9 and 10 compare the case of Level 1 with Level 2. It can be seen that the $\mathrm{H}_{2}$ obtained in the case of Level 2 was highest when $20 \%$ of the fuel was replaced with biomass. Nevertheless, a slight decrease in $\mathrm{CO}$ production was observed, as the production of $\mathrm{CO}_{2}$ increased. The gasification of coal mixed with biomass is conducive to the formation of $\mathrm{H}_{2}$, so less $\mathrm{H}_{2} \mathrm{O}$ is retained in the gasifier. This phenomenon could be due to the lower amount of volatiles released by coal mixed with biomass, which would have a greater availability of oxygen to be oxidized leading to an increase in $\mathrm{CO}_{2}$ production to the detriment of $\mathrm{CO}$. The preceding characteristics are consistent with results of Fermoso et al. [36]. With regard to coal gasification in Level 3, the concentrations of $\mathrm{H}_{2} \mathrm{O}$ and $\mathrm{CO}_{2}$ are the lowest among the three cases. These results may come from the lower $\mathrm{O} / \mathrm{F}$ ratio impeding the combustion reaction process. Consequently, a lower $\mathrm{O} / \mathrm{F}$ ratio is conducive to $\mathrm{CO}$ formation; whereas a higher $\mathrm{O} / \mathrm{F}$ ratio increases the formation of $\mathrm{H}_{2}$. In addition, the concentration of $\mathrm{CH}_{4}$ is extremely low $(<0.01 \%)$ in all cases; hence the concentration contours of methane are not presented. 


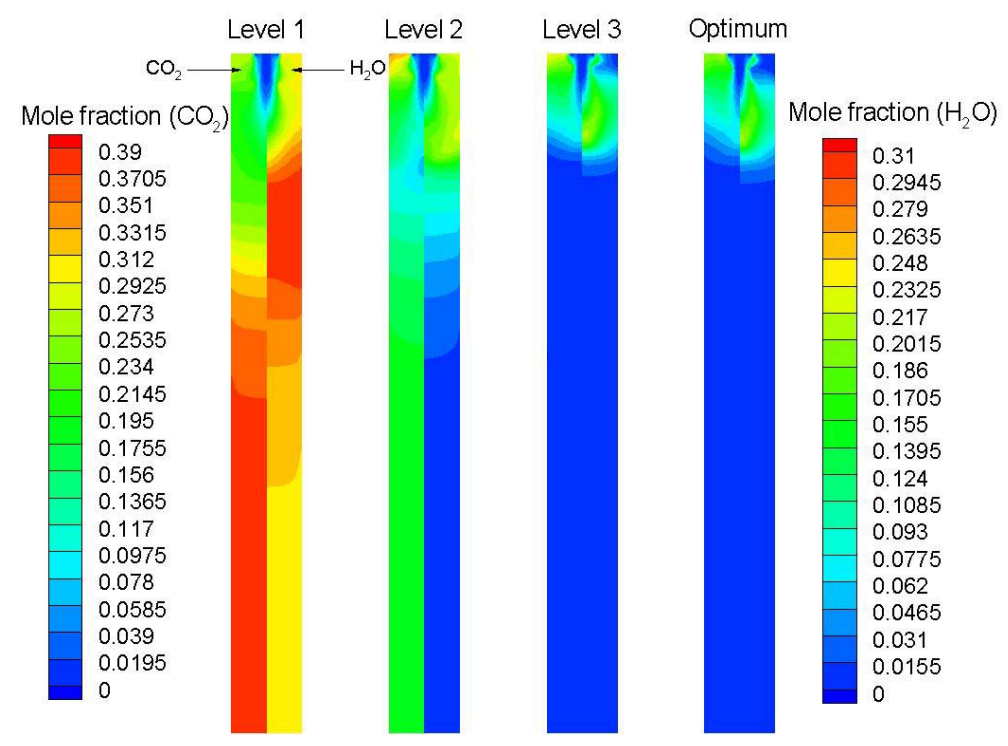

Fig. 10. Concentration profiles of $\mathrm{CO}_{2}$ and $\mathrm{H}_{2} \mathrm{O}$ of the gasification of original cases and the optimum case.

Based on the above analysis, the optimum condition is achieved as A1B3C3D3. Subsequently, the results can be given as follows: wall temperature is $1500 \mathrm{~K}, \mathrm{O} / \mathrm{F}$ ratio is 0.6 , feed type is coal, and gasifier pressure is $3 \mathrm{MPa}$. Using Equation (29), the $\mathrm{S} / \mathrm{N}$ ratio is 13.4, which is higher than the other original cases. This result suggests that the choice of significant factors is appropriate; therefore, the result verifies that the optimizing result based on the Taguchi method is robust.

\section{Conclusions}

This paper presented an optimization analysis of the gasification process in an entrained-flow gasifier through the application of the Taguchi method in conjunction with a simulation method. The following conclusions can be derived:

(1). By comparing the results of the temperature distribution test and the chemical reaction test for the gasification phenomenon, verification of the hypothesis for the CFD model is shown to be reasonable. The numerical predictions are in good agreement with the experimental data. Therefore, the gasification reaction process may be further studied by the CFD model.

(2). The effects of the control conditions in the gasification process can be analyzed by the Taguchi method. The influence strength order of each factor is feed type $>\mathrm{O} / \mathrm{F}$ ratio $>$ wall temperature $>$ pressure. The values of the $\mathrm{S} / \mathrm{N}$ ratio for the original cases of Level 1, Level 2, Level 3, and the optimum case are 1.01, 8.96, 13.09, and 13.40, respectively. The optimum case has the highest $\mathrm{S} / \mathrm{N}$ ratio.

(3). The gasification phenomena of three different fuel types, including bamboo, coal mixed with bamboo, and pure coal, in an entrained-flow gasifier have been explored and compared with each other using a numerical method. In view of the significant differences in the calorific values of bamboo and coal, the reaction temperature in the gasifier is significantly affected by the feedstock. From the analysis of the $\mathrm{O} / \mathrm{F}$ ratio, a lower $\mathrm{O} / \mathrm{F}$ ratio impedes the combustion reaction process. Consequently, a lower $\mathrm{O} / \mathrm{F}$ ratio is conducive to $\mathrm{CO}$ formation, whereas a higher $\mathrm{O} / \mathrm{F}$ ratio increases the 
formation of $\mathrm{H}_{2}$.

(4). Using the Taguchi method, the optimum conditions of the gasification process were investigated. The results show that the Taguchi method is able to modify the gasification process well, indicating that the optimum condition of the gasification process in the gasifier is $\mathrm{A} 1 \mathrm{~B} 3 \mathrm{C} 3 \mathrm{D} 3$. The conditions are as follows: wall temperature is $1500 \mathrm{~K}, \mathrm{O} / \mathrm{F}$ ratio is 0.6 , feed type is coal and gasifier pressure is $3 \mathrm{MPa}$.

\section{Acknowledgments}

The authors gratefully acknowledge the financial support of the National Science Counsel, Taiwan, ROC, on this study.

\section{Notations}

$A$ : Pre-exponential factor

$B$ : Temperature exponent

$C$ : Molecular concentration

or Turbulence constant

$c_{p}:$ Specific heat

$d_{p}$ : Particle diameter

$D$ : Diffusion coefficient

$E_{a}$ : Activation energy

$\left[\mathrm{kmol} \mathrm{m}^{-3}\right]$

$G_{k}$ : Generation of turbulence kinetic energy

[ $\left.\mathrm{J} \mathrm{kgK}^{-1}\right]$

[m]

$\left[\mathrm{m}^{2} \mathrm{~s}^{-1}\right]$

$\Delta H^{0}$ : Heat of reaction (at $298 \mathrm{~K}$ and $1 \mathrm{~atm}$ )

$\left[\mathrm{J} \mathrm{kmol}^{-1}\right.$ ]

$K_{e q}$ : Equilibrium reaction rate

$k$ : Reaction rate constant

or Turbulence kinetic energy $\left[\mathrm{m}^{2} \mathrm{~s}^{-2}\right]$

$L$ : Loss

$M$ : Molecular weight

$m$ : Mass

$\left[\mathrm{kg} \mathrm{mol}^{-1}\right]$

$N$ : Reaction apparent order

[kg]

Pr: Prandtl number

$p$ : Pressure

$r$ : Radial coordinate

or Species reaction rate per unit area

$R$ : Universal gas constant

$\bar{R}$ : Species consumption rate at particle surface

$S$ : Source term

Sc: Schmidt number

$S_{r}$ : Summation of species reaction rates

$T$ : Temperature

or Target response

$T_{P}$ : Fuel particle temperature

$[\mathrm{Pa}]$

[m]

$\left[\mathrm{kg} \mathrm{m}^{-2} \mathrm{~s}^{-1}\right]$

[ $\mathrm{J} \mathrm{kmolK}^{-1}$ ]

$\left[\mathrm{kg} \mathrm{m}^{-2} \mathrm{~s}^{-1}\right]$

$t$ : Time

$u$ : Gas velocity component

$\left[\mathrm{kg} \mathrm{m}^{-2} \mathrm{~s}^{-1}\right]$

[K]

$V$ : Mass fraction of volatiles

[K]

[s]

$v_{r}$ : Stoichiometric coefficient of reaction $r$

$\left[\mathrm{m} \mathrm{s}^{-1}\right]$

$w$ : Reaction rate

$x$ : Coordinate

$\left[\mathrm{kg} \mathrm{m}^{-3} \mathrm{~s}^{-1}\right]$

$Y$ : Stoichiometric coefficient

[m] or Species

$y$ : Mass fraction

or Measured response

$z$ : Axial coordinate

\section{Greek letters}

$\alpha$ : Molecular fraction 
$\varepsilon:$ Turbulence dissipation rate

$\lambda:$ Thermal conductivity

$\mu$ : Viscosity

$\rho:$ Density

$\tau_{i j}$ : Symmetric stress tensor

$\eta$ : Rate exponent for species

Subscript

$D$ : Drag

$f$ : Forward

$h$ : High temperature

or Energy

$i$ : Species $i$

or Spatial coordinate

$j$ : Momentum

or Spatial coordinate

or Species $j$

$l$ : Low temperature

$P$ : Fuel particle

$r$ : Reaction

$t$ : Turbulence

$k$ : Kinetic energy

$\mu$ : Viscosity

$\varepsilon:$ Dissipation

\section{References}

$\left[\mathrm{m}^{2} \mathrm{~s}^{-3}\right]$

[W mK $\left.\mathrm{WH}^{-1}\right]$

$\left[\mathrm{kg} \mathrm{ms}^{-1}\right]$

$\left[\mathrm{kg} \mathrm{m}^{-3}\right]$

$\left[\mathrm{kg} \mathrm{m}^{-1} \mathrm{~s}^{-2}\right]$

[1] BP. Statistical Review of World Energy; 2012.

[2] Smoot L.D., "Fundamentals for Coal Combustion: for Clean and Efficient Use", Elsevier, New York (1993).

[3] Pettinau A. et al., "Techno-economic comparison between different technologies for a CCS power generation plant integrated with a sub-bituminous coal mine in Italy", Applied Energy, 99 (2012), 32-39.

[4] Chen W.H. et al., "Transient gasification and syngas formation for coal particles in a fixed-bed reactor" International Journal of Energy Research, 31 (2007), 895-911.

[5] Pan Y.G. et al., "Fluidized-bed co-gasification of residual biomass/poor coal blends for fuel gas production", Fuel, 79 (2000), 1317-1326.

[6] Taguchi G., "Introduction to Quality Engineering”, McGraw-Hill, New York (1990)

[7] Chou C.S. et al., "The optimum conditions for combination of magnetic particles driven by a rotating magnetic field using the Taguchi method" Advanced Powder Technology, 20 (2009), 55-61.

[8] Singaravelu J.et al., "Taguchi's approach for reliability and safety assessments in the stage separation process of a multistage launch vehicle", Reliability Engineering \& System Safety, 94 (2009), 1526-1541.

[9] Zolfaghari G.h. et al., 2011. "Taguchi optimization approach for $\mathrm{Pb}$ (II) and $\mathrm{Hg}(\mathrm{II})$ removal from aqueous solutions using modified mesoporous carbon", Journal of Hazardous Materials, 192 (2011), 1046-1055.

[10] Dingal S. et al., 2008. "The application of Taguchi's method in the experimental investigation of the laser sintering process", The International Journal of Advanced Manufacturing Technology, 38 (2008), 904-914.

[11] Zhang J.Z. et al., "Surface roughness optimization in an end milling operation using the Taguchi design method", Journal of Materials Processing Technology, 184 (2007), 233-239.

[12] Lakshminarayanan A.K. and Balasubramanian V., "Process parameters optimization 
for friction stir welding of RDE-40 aluminum alloy using Taguchi technique", Transactions of Nonferrous Metals Society of China, 18 (2008), 548-554.

[13] Rosa, J.L. et al., 2009. "Electro-deposition of copper on titanium wires: Taguchi experimental design approach", Journal of Materials Processing Technology, 209 (2009), 1181-1188.

[14] Wu H.W. and Ku K.H., "The optimal parameters estimation for rectangular cylinders installed transversely in the flow channel of PEMFC from a three-dimensional PEMFC model and the Taguchi method", Applied Energy, 88 (2011), 4879-4890.

[15] $\mathrm{Wu} \mathrm{H.W.} \mathrm{and} \mathrm{Ku} \mathrm{K.H.,} \mathrm{"Effects} \mathrm{of} \mathrm{modified} \mathrm{flow} \mathrm{field} \mathrm{on} \mathrm{optimal} \mathrm{parameters}$ estimation and cell performance of a PEM fuel cell with the Taguchi method", International Journal of Hydrogen Energy, 37 (2012), 1613-1627.

[16] Chary G.H.V.C. and Dastidar M.G., "Investigation of optimum conditions in coal-oil agglomeration using Taguchi experimental design”, Fuel, 98 (2012), 259-264.

[17] Park C.L. and Kim B.G., "The optimization of low-rank coal grinding for transport coal gasification by robust design", Fuel, 95 (2012), 282-286.

[18] Shen C.H. et al., "Co-gasification performance of coal and petroleum coke blends in a pilot-scale pressurized entrained-flow gasifier", International Journal of Energy Research, 36 (2012), 499-508.

[19] Launder B.E. and Spalding D.B., "The numerical computation of turbulent flows", Computer Methods in Applied Mechanics and Engineering, 3 (1974), 269-289.

[20] Silaen A. and Wang T., "Effect of turbulence and devolatilization models on coal gasification simulation in an entrained-flow gasifier", International Journal of Heat and Mass Transfer, 53 (2010), 2074-2091.

[21] Chen W.H. et al., "Volatile release and particle formation characteristics of injected pulverized coal in blast furnace", Energy Conversion and Management, 48 (2007), 2025-33.

[22] Du S.W. et al., "Performance of pulverized coal injection in blowpipe and tuyere at various operational conditions", Energy Conversion and Management, 48 (2007), 2069-2076.

[23] Du S.W. and Chen W.H., "Numerical simulation and practical improvement of pulverized coal combustion in blast furnace", International Communications in Heat and Mass Transfer, 33 (2006), 327-34.

[24] Roberts D.G. and Harris D.J., "Char gasification with O2, CO2 and H2O: effects of pressure on intrinsic reaction kinetics”, Energy Fuels, 14 (2000), 483-489.

[25] Jones W.P. and Lindstedt R.P., "Global reaction schemes for hydrocarbon combustion", Combustion and Flame, 73 (1988), 233-249.

[26] Macias-Garcia A. et al., "Application of the Rosin-Rammler and Gates-Gaudin-Schuhmann models to the particle size distribution analysis of agglomerated cork", Materials Characterization, 52 (2004), 159-164.

[27] Rousset P. et al., "Enhancing the combustible properties of bamboo by torrefaction", Bioresource Technology, 102 (2011), 8225-8231.

[28] Chen W.H., "A simplified model of predicting coal reaction in a partial oxidation environment", International Communications in Heat and Mass Transfer, 34 (2007), 623-629.

[29] Chmielniak T. and Sciazko M., "Co-gasification of biomass and coal for methanol synthesis", Applied Energy, 74 (2003), 393-403.

[30] Valero A. and Uson S., "Oxy-co-gasification of coal and biomass in an integrated gasification combined cycle (IGCC) power plant”, Energy, 31 (2006), 1643-1655.

[31] Lapuerta M. et al., "Gasification and co-gasification of biomass wastes: Effect of the biomass origin and the gasifier operating conditions", Fuel Processing Technology, 89 (2008), 828-837. 
[32] Cormos C.C., "Hydrogen and power co-generation based on coal and biomass/solid wastes co-gasification with carbon capture and storage", International Journal of Hydrogen Energy, 37 (2012), 5637-5648.

[33] Jones W.P. and Lindstedt R.P., "Global reaction schemes for hydrocarbon combustion", Combustion and Flame, 73 (1988), 233-249.

[34] Chen C.J. et al., "Numerical investigation on performance of coal gasification under various injection patterns in an entrained flow gasifier", Applied Energy, 100 (2012), 218-228.

[35] Vicente W. et al., "An Eulerian model for the simulation of an entrained flow coal gasifier”, Applied Thermal Engineering, 23 (2003), 1993-2008.

[36] Fermoso J. et al., "Co-gasification of different rank coals with biomass and petroleum coke in a high-pressure reactor for H2-rich gas production”, Bioresource Technology, 101 (2010), 3230-3235. 